\title{
Development of a measurement tool to assess public awareness
} of cancer

\author{
S Stubbings', K Robb', J Waller', A Ramirez ${ }^{2}$, J Austoker ${ }^{3}$, U Macleod ${ }^{4}$, S Hiom $^{5}$ and J Wardle*, \\ 'Cancer Research UK Health Behaviour Research Centre, Department of Epidemiology and Public Health, UCL, Gower Street, London WCIE 6BT, UK; \\ ${ }^{2}$ Cancer Research UK Promoting Early Presentation Group, Institute of Psychiatry, King's College London, St Thomas' Hospital, London, UK; ${ }^{3}$ Cancer \\ Research UK Primary Care Education Research Group, Cancer Epidemiology Unit, University of Oxford, Richard Doll Building, Roosevelt Drive, Oxford, UK; \\ ${ }^{4}$ General Practice and Primary Care, Division of Community Based Sciences, Faculty of Medicine, University of Glasgow, I Horselethill Road, Glasgow, UK; \\ ${ }^{5}$ Health Information Department, Cancer Research UK, 6 I Lincoln's Inn Fields, London, UK
}

BACKGROUND: We aimed to develop and validate a measurement tool to assess cancer awareness in the general population: the cancer awareness measure (CAM).

METHODS: Items assessing awareness of cancer warning signs, risk factors, incidence, screening programmes and attitudes towards help seeking were extracted from the literature or generated by expert groups. To determine reliability, the CAM was administered to a university participant panel $(n=148)$, with a sub-sample $(n=94)$ completing it again 2 weeks later. To establish construct validity, CAM scores of cancer experts $(n=12)$ were compared with those of non-medical academics $(n=21)$. Finally, university students $(n=49)$ were randomly assigned to read either a cancer information leaflet or a leaflet with control information before completing the measure, to ensure the CAM was sensitive to change.

RESULTS: Cognitive interviewing indicated that the CAM was being interpreted as intended. Internal reliability (Cronbach's $\alpha=0.77)$ and test-retest reliability $(r=0.8 \mathrm{I})$ were high. Scores for cancer experts were significantly higher than those for non-medical academics $(t(3 \mathrm{I})=6.8, P<0.00 \mathrm{I})$. CAM scores were higher among students who received an intervention leaflet than the control leaflet $(t(47)=4.8, P<0.001)$.

CONCLUSIONS: These studies show the psychometric properties of the CAM and support its validity as a measure of cancer awareness in the general population.

British Journal of Cancer (2009) I 0 I, SI3-SI7. doi:I0.1038/sj.bjc.6605385 www.bjcancer.com

(c) 2009 Cancer Research UK

Keywords: cancer awareness; measurement; psychometrics

Cancer is a major burden worldwide (Parkin et al, 2005) and a leading cause of mortality in the United Kingdom, claiming over 150000 lives a year (Cancer Research UK, 2009). Around 289000 new cases are diagnosed annually in the United Kingdom, with one in three people developing cancer in their lifetime (Cancer Research UK, 2008a). Despite progress in reducing mortality rates, changes in the age distribution of the population will mean that cancer incidence will continue to rise (Boyle and Ferlay, 2005). In recent years, the UK Governments have developed strategies aimed at reducing cancer incidence and mortality; the most recent for England is the NHS Cancer Reform Strategy (Department of Health, 2007), which emphasises the importance of raising public awareness of early warning signs and risk factors.

Existing evidence indicates that public awareness of warning signs is poor. In a population-based survey in England, fewer than 1 in 10 respondents could recall Europe Against Cancer's seven warning signs for cancer (Brunswick et al, 2001). These findings are not unique to this study nor limited to generic warning signs; awareness is also low for a range of cancers (Wardle et al, 2001;

\footnotetext{
*Correspondence: Professor J Wardle; E-mail: j.wardle@ucl.ac.uk
}

Grunfeld et al, 2002; McCaffery et al, 2003; Rudberg et al, 2005; West et al, 2006; FitzGerald et al, 2008).

European comparisons show the United Kingdom to have lower than average cancer survival rates (Coleman et al, 2003), part of which is due to patients in the United Kingdom having more advanced stage of disease at diagnosis. Later presentation of cancer symptoms in the United Kingdom than in other European countries may contribute to this. Raising public awareness of warning signs and promoting prompt presentation could reduce patient-attributable delay and result in diagnosis at an earlier stage (Ramirez et al, 1999; Richards et al, 1999; Macdonald et al, 2006).

Awareness of cancer risk factors except for tobacco use is also low (Wardle et al, 2001; Grunfeld et al, 2002; McCaffery et al, 2003; Marlow et al, 2007; Redeker et al, 2009), particularly in relation to weight, alcohol consumption, high-fat diet, exercise and older age. It is estimated that around half of all cancers could be prevented by modification of lifestyle risk factors (Cancer Research UK, 2008b). Although awareness alone may not be sufficient to motivate change, it is unrealistic to expect changes in behaviour if people are not at least aware of the risk factors (Viswanath et al, 2006).

There is currently no validated measure of general public awareness of cancer, although several questionnaires have been 
developed to assess awareness of specific cancers (Stager, 1993; Rees et al, 2003; Green and Kelly, 2004). In a review of the literature, Adlard and Hume (2003) also identified lack of agreement over the best way to measure cancer awareness. As a result, different question formats are often used. Questions asked in a prompted (recognition) format can elicit higher apparent levels of cancer awareness than those asked in an unprompted (recall) format (Waller et al, 2004). Such variations in responses make it difficult to establish current levels of awareness or make comparisons across studies.

Education campaigns designed to improve awareness of cancer in the general population have been carried out, but without validated instruments, it is difficult to evaluate effectiveness. This highlights the need for a measure that will enable both researchers and campaigning groups to evaluate the impact of their activities.

The aim of this research was therefore to develop and validate a standardised measurement tool to assess cancer awareness. A good measure should have face validity, the questions should be interpreted as intended by the target audience, and it should give stable results across two occasions between which knowledge has not changed (test-retest reliability). Good reliability is essential for obtaining precise estimates of knowledge and for giving the best statistical power to detect change. A good measure also needs to be valid, that is, groups who by general consensus have a higher standing on the relevant constructs should score higher; in this case, we compared cancer experts and equivalently educated nonexperts to test the instrument's sensitivity to knowledge. Finally, if it is to have value in assessing the impact of public health interventions, it should be sensitive to change; we tested this by comparing scores before and after exposure to a brief educational intervention.

\section{MATERIALS AND METHODS}

\section{Generation of items}

Following a review of the literature, existing awareness questionnaires were examined and relevant items extracted. This was supplemented with a review of the 'grey' literature (i.e. unpublished surveys carried out by cancer charities and other organisations) to include items not published in academic journals. Following this review, an item pool consisting of 137 items was created. These covered a range of topics including awareness of warning signs and risk factors, cancer incidence and awareness of national screening programmes. Items were then excluded if they were poorly worded, used terminology not frequently used in the United Kingdom (e.g. Pap test) or were attitudinal in nature (e.g. 'I believe there are no early symptoms of cancer'). Items relating to awareness of the purpose of screening, the benefits of early detection and cancer survival rates were also omitted from the measure because the primary focus was symptom recognition. In addition, the research team generated several items specifically for the instrument that had not been used in previous questionnaires.

Once consensus over the items had been reached, a first version of the cancer awareness measure (CAM) was circulated to a panel of experts $(n=16)$ including academic researchers, cancer charity representatives, general practitioners, oncologists and experts in the field of questionnaire design, to ensure content validity and face validity. In addition, cognitive interviews were conducted with the general public. These encourage respondents to verbalise their cognitions, making it possible to identify areas where interpretation of the questions is ambiguous (Collins, 2003). Cognitive interviews were conducted with a small sample of participants $(n=6)$ aged between 23 and 70 years. Minor modifications were made to the phrasing of several items as a result.

The final version of the CAM consisted of the following: (i) 10 items on awareness of warning signs (one open-ended question and nine recognition items); (ii) nine items on anticipated time to seek medical advice (asking about each of the warning signs); (iii) 10 items on barriers to seeking medical advice (covering a range of practical, service delivery and emotional barriers); (iv) 13 items on awareness of risk factors (one open-ended question, 11 recognition items and one asking participants to rank the importance of different types of risk factor); (v) seven items on cancer incidence (one asking about overall cancer incidence and six asking about the three most common cancers for men and women) and (vi) six items on awareness of NHS screening programmes (asking about awareness of the cervical, breast and bowel screening programmes and the age from which screening is offered for each).

\section{Validating the CAM}

Validating the CAM was a three-stage process, with each stage assessing a different aspect of reliability or validity. The aims of stage one were to establish internal reliability and test-retest reliability and carry out item analyses; stage two was designed to establish construct validity and stage three to ensure that the measure was sensitive to increases in levels of awareness.

Data were analysed using SPSS 14.0. Parametric statistics (e.g. Pearson's correlation, $t$-tests) were performed to analyse the reliability and validity of the measure. Descriptive statistics were used to examine the characteristics of the samples.

\section{RESULTS}

\section{Stage 1: Internal reliability and test-retest reliability}

Sample and methods Five hundred and fifty-one e-mails were sent to a research 'participant panel' with an invitation to complete the CAM anonymously online. The panel consisted of members of the general public who had previously indicated that they were willing to participate in research. The questionnaire was completed in the available time by $148(27 \%)$ panel members. The majority of respondents were women $(76 \%)$, white $(86 \%)$ and educated to degree level (68\%) (Table 1). Two weeks later, respondents were asked to complete the CAM a second time. Two weeks was judged as an adequate period of time for respondents neither to recall precisely their original answers, nor to be likely to have had any major changes in cancer awareness. Ninety-four participants $(63 \%)$ completed the questionnaire again. Data were matched using e-mail addresses.

Internal reliability assesses the extent to which all the questionnaire items measure the same underlying construct (Kline, 2000). It is assessed using Cronbach's $\alpha$ and a minimum score of 0.7 should be obtained for a questionnaire to be considered reliable (Bland and Altman, 1997). To assess the stability of a questionnaire over time, a measure of test-retest reliability must be calculated (Kline, 2000). Pearson's correlations are computed using scores from two time points. It is important to identify whether respondents find items too easy or too difficult to answer, and it is recommended that items are excluded if they are answered correctly by $>80 \%$ or $<20 \%$ of participants (Kline, 2000 ). Item discrimination reveals the ability of an individual item to discriminate between those who have high or low overall knowledge scores, and items should be discarded if an item-tototal correlation of $<0.2$ is yielded (Streiner and Norman, 1995).

\section{Analysis and results}

Internal reliability A Cronbach's $\alpha$ of 0.77 was achieved for the whole questionnaire, with the following $\alpha$ values obtained for each sub-section: warning signs (9 recognition items) 0.77; anticipated time to seek medical advice ( 9 items) 0.90 ; barriers to seeking medical advice (10 items) 0.73; risk factors (11 recognition items) 0.79; NHS screening programmes (6 items) 0.54 . Despite obtaining 
Table I Demographic characteristics of the online study sample $(n=148)$

\begin{tabular}{|c|c|c|}
\hline & $N$ & $\%^{a}$ \\
\hline \multicolumn{3}{|l|}{ Gender } \\
\hline Male & 36 & 24.3 \\
\hline Female & 112 & 75.7 \\
\hline \multicolumn{3}{|l|}{ Age (years) } \\
\hline $18-24$ & 40 & 27.0 \\
\hline $25-34$ & 33 & 22.3 \\
\hline $35-44$ & 9 & 6.1 \\
\hline $45-54$ & || & 7.4 \\
\hline $55-64$ & 39 & 26.4 \\
\hline 65 and over & 16 & 10.8 \\
\hline \multicolumn{3}{|l|}{ Ethnic origin } \\
\hline White & 126 & 85.1 \\
\hline Other & 20 & 13.5 \\
\hline \multicolumn{3}{|l|}{ Employment status } \\
\hline Employed full-time & 37 & 25.0 \\
\hline Employed part-time & || & 7.4 \\
\hline Student & 62 & 41.9 \\
\hline Other & 38 & 25.7 \\
\hline \multicolumn{3}{|c|}{ Highest qualification obtained } \\
\hline No qualifications & 2 & 1.4 \\
\hline O level/GCSE & 5 & 3.4 \\
\hline A level & 14 & 9.5 \\
\hline Degree or above & 101 & 68.2 \\
\hline Still studying & 23 & 15.5 \\
\hline \multicolumn{3}{|l|}{ Marital status } \\
\hline Single & 58 & 39.2 \\
\hline Married/cohabiting & 75 & 50.7 \\
\hline Divorced/widowed & 14 & 9.5 \\
\hline
\end{tabular}

a Some variables do not add up to $100 \%$ due to missing data

an $\alpha$ below the minimum cutoff, the decision was made to retain awareness of NHS screening programmes on the grounds of content validity.

Test-retest reliability With the exception of incidence of common cancers, high correlations over time were found for all sections (Table 2), all of which reached statistical significance $(P<0.001)$.

Item difficulty The majority of items matched the criterion of being answered correctly by $<80 \%$ and $>20 \%$ of participants. The few that did not were retained on the basis of face validity (e.g. smoking being a risk factor for cancer, a lump being a warning sign for cancer), because respondents might be surprised if they were not included.

Item discrimination Analyses revealed item-to-total correlations $>0.2$ for each item, suggesting all items in the CAM should be retained.

\section{Stage 2: Construct validity: cancer 'experts' $v$ s non-medical academics}

Sample and methods The 'known-groups' method was used to establish construct validity. If the scores of two groups known to differ in levels of cancer awareness are significantly different then the validity of the questionnaire is supported (DeVellis, 2003). Cancer experts $(n=12)$ were recruited from a large cancer charity, while the 'non-expert' group comprised non-medical academics
Table 2 Test-retest reliability of the CAM $(n=94)$

\begin{tabular}{lc}
\hline Awareness section & Test-retest reliability \\
\hline Warning signs & 0.73 \\
Anticipated time to seek advice & 0.86 \\
Barriers to seeking advice & 0.72 \\
Risk factors & 0.73 \\
Incidence per I00 people & 0.78 \\
Incidence - common cancers & 0.33 \\
Screening programmes & 0.75 \\
Screening programmes - age at first invitation & 0.77 \\
Total & 0.81
\end{tabular}

Abbreviation: $C A M=$ cancer awareness measure

Table 3 Demographic characteristics of the two samples $(n=33)$

\begin{tabular}{|c|c|c|c|c|}
\hline & \multicolumn{2}{|c|}{$\begin{array}{l}\text { Non-medical academics } \\
\qquad(n=2 I)\end{array}$} & \multicolumn{2}{|c|}{$\begin{array}{c}\text { Cancer experts } \\
(n=12)\end{array}$} \\
\hline & $n$ & $\%$ & $n$ & $\%$ \\
\hline \multicolumn{5}{|l|}{ Age (years) } \\
\hline $25-34$ & 2 & 9.5 & 7 & 58.3 \\
\hline $35-44$ & 8 & 38.1 & 4 & 33.3 \\
\hline $45-54$ & 9 & 42.9 & - & - \\
\hline $55-64$ & 2 & 9.5 & I & 8.3 \\
\hline \multicolumn{5}{|l|}{ Gender } \\
\hline Male & 9 & 42.9 & 1 & 8.3 \\
\hline Female & 12 & 57.1 & | | & 91.7 \\
\hline \multicolumn{5}{|l|}{ Highest qualification } \\
\hline Degree & - & - & 2 & 16.7 \\
\hline Masters & 2 & 9.5 & 3 & 25.0 \\
\hline PhD or equivalent & 19 & 90.5 & 5 & 41.7 \\
\hline Other & - & - & 2 & 16.7 \\
\hline
\end{tabular}

$(n=21)$ recruited from a range of departments in the university. Participants were invited to take part by e-mail and could either complete the questionnaire electronically or print it out and complete a paper copy. The demographic characteristics of the samples can be seen in Table 3.

\section{Analyses and results}

The cancer experts scored consistently higher than the nonmedical academics (Table 4) and, with the exception of incidence, this reached statistical significance for each awareness section. Although differences in incidence scores were not statistically significant, the standard deviations varied considerably ( 0.8 for the cancer experts and 12.5 for the non-medical group), suggesting that experts were more consistent at answering the questions.

\section{Stage 3: Sensitivity to change: brief educational intervention}

Sample and methods A convenience sample of 49 undergraduate and postgraduate students was recruited to participate in this stage. They were randomised to receive one of two leaflets to read before completing a paper copy of the CAM. One was an educational leaflet ('Cancer: the facts'), which included information on the aetiology of cancer, incidence rates, warning signs, risk factors and available NHS screening programmes. The other was a control leaflet ('Recycle to save the environment'). 
Table 4 Differences in awareness scores between non-medica academics and cancer experts $(n=33)$

\begin{tabular}{|c|c|c|c|c|c|}
\hline \multirow{2}{*}{$\begin{array}{l}\text { Awareness section } \\
\text { (max score) }\end{array}$} & \multicolumn{2}{|c|}{$\begin{array}{l}\text { Non-medical } \\
\text { academics } \\
(n=2 I)\end{array}$} & \multicolumn{2}{|c|}{$\begin{array}{l}\text { Cancer } \\
\text { experts } \\
(n=12)\end{array}$} & \multirow[b]{2}{*}{$t(31)$} \\
\hline & Mean & s.d. & Mean & s.d. & \\
\hline Warning signs (9) & 7.3 & 2.4 & 8.8 & 0.4 & $2.9 *$ \\
\hline Risk factors (55) & 42.3 & 4.1 & 50.8 & 4.7 & $5.4 * *$ \\
\hline Incidence per 100 people ${ }^{a}$ & 34.0 & 12.5 & 33.3 & 0.8 & -0.2 \\
\hline Incidence - common cancers (6) & 2.3 & 1.2 & 3.5 & 1.4 & $2.7 *$ \\
\hline Screening programmes (3) & 1.9 & 0.4 & 3.0 & 0.0 & $9.4 * *$ \\
\hline $\begin{array}{l}\text { Screening programmes - age at } \\
\text { first invitation (3) }\end{array}$ & 0.7 & 0.6 & 2.2 & I.I & $4.2 * *$ \\
\hline Total (77) & 57.2 & 5.9 & 69.3 & 5.6 & $6.8 * *$ \\
\hline
\end{tabular}

Table 5 Demographic characteristics of the two samples $(n=49)$

\begin{tabular}{|c|c|c|c|c|}
\hline & \multicolumn{2}{|c|}{ Control $(n=24)$} & \multicolumn{2}{|c|}{ Intervention $(n=25)$} \\
\hline & $n$ & $\%$ & $n$ & $\%$ \\
\hline \multicolumn{5}{|l|}{ Age (years) } \\
\hline $18-24$ & 9 & 62.5 & 12 & 48.0 \\
\hline $25-34$ & 15 & 37.5 & 12 & 48.0 \\
\hline $35+$ & - & - & । & 4.0 \\
\hline \multicolumn{5}{|l|}{ Gender } \\
\hline Male & 9 & 37.5 & 9 & 36.0 \\
\hline Female & 15 & 62.5 & 16 & 64.0 \\
\hline \multicolumn{5}{|c|}{ Ethnic origin } \\
\hline White & 17 & 70.8 & 16 & 64.0 \\
\hline Other & 7 & 29.2 & 9 & 36.0 \\
\hline
\end{tabular}

Table 6 Differences in awareness scores between control and intervention participants $(n=49)$

\begin{tabular}{|c|c|c|c|c|c|}
\hline \multirow{2}{*}{$\begin{array}{l}\text { Awareness section } \\
\text { (max score) }\end{array}$} & \multicolumn{2}{|c|}{$\begin{array}{l}\text { Control } \\
(n=24)\end{array}$} & \multicolumn{2}{|c|}{$\begin{array}{l}\text { Intervention } \\
(n=25)\end{array}$} & \multirow[b]{2}{*}{$t(47)$} \\
\hline & Mean & s.d. & Mean & s.d. & \\
\hline Warning signs (9) & 6.0 & 1.9 & 7.3 & 0.9 & $2.7 *$ \\
\hline Risk factors (55) & 39.8 & 4.6 & 43.7 & 5.0 & $2.8 *$ \\
\hline Incidence per 100 people ${ }^{a}$ & 29.2 & 11.5 & 32.8 & 3.4 & 1.5 \\
\hline Screening programmes (3) & 1.8 & 0.7 & 2.7 & 0.7 & $4.2 * *$ \\
\hline $\begin{array}{l}\text { Screening programmes - age at } \\
\text { first invitation (3) }\end{array}$ & 0.6 & 0.6 & 1.8 & 0.9 & $5.2 * *$ \\
\hline Total $(7 \mathrm{I})^{\mathrm{b}}$ & 48.7 & 5.8 & 56.3 & 5.7 & $4.6 * *$ \\
\hline
\end{tabular}

Demographic characteristics of the two groups were similar (Table 5), with no significant differences in age, gender or ethnic origin being observed.

\section{Analyses and results}

The cancer education group scored consistently higher than the control group and, excluding results for cancer incidence, this reached statistical significance for all awareness sections (Table 6). Not surprisingly for such a brief intervention there was comparatively small mean difference between the education and control groups, but there was also differentiated variability with standard deviations of 3.4 (education) and 11.5 (control).

\section{DISCUSSION}

There has been a good deal of interest in public awareness of cancer, but in most studies measures are developed on an ad hoc basis, often with a specific population in mind, and rarely address psychometric properties. This not only limits generalisation to other groups, but also precludes comparisons between studies or groups.

The CAM was developed to provide a validated measure of awareness of early warning signs and risk factors, and barriers to seeking medical advice. Reliability of the measure was high, with a total Cronbach's $\alpha$ of 0.77 and all but one of the sub-scales reaching the recommended cutoff of 0.7 . Test - retest reliability was also good, with all sub-scales except awareness of the incidence of common cancers being $>0.7$. The low reliability of the incidence items probably reflects the fact that people had little idea and were just guessing the answers; and not making the same guess on different occasions. This is understandable because although people may be able to identify the most common cancer in men (prostate) and women (breast), the second and third most common cancers are rarely publicised as such. However, given that awareness of the most common cancers could improve, these items were retained.

Construct validity was established using a 'known-groups' design. Overall, those with expertise in cancer achieved significantly higher mean scores than non-medical academics, showing the CAM has the ability to distinguish between groups with established differences in levels of awareness. In addition, the CAM was shown to be sensitive to increases in awareness following a brief educational intervention.

\section{Limitations}

The limitations to the validation of the measure should be noted. The mode of administration varied across different stages of piloting, including online and with paper-and-pencil versions. Concerns have been raised about the quality of survey data collected through different modes (Bowling, 2005), although the mode of administration was consistent within each stage of piloting so the potential impact would have been kept to a minimum. For use in population surveys, we suggest that the CAM should ideally be given in an interview format to prevent participants from changing their previous answers in response to the prompted format of subsequent questions. The pilot samples tended to be female and educated to degree level, which limits generalisation to other populations. However, given that the CAM was sensitive to differences in levels of awareness in a highly educated academic sample, it is likely that differences would be equally marked in less educated populations. To date, the CAM is only available in English, but we anticipate that it will be translated into a range of languages and available for use in the future.

\section{Future work}

This paper describes the development of the generic CAM. Work is now underway to develop tumour-specific versions of the CAM, including breast, prostate, bowel, cervical and ovarian, and more tumour-specific versions are planned. It is anticipated that the CAM will evolve over time to reflect advances in knowledge, and to 
include items on cancer beliefs that may help us to better understand cancer-related behaviour.

\section{CONCLUSION}

The CAM is a reliable and valid measure of cancer awareness and can be used to provide a comprehensive assessment of cancer awareness. The CAM has now been administered in a large-scale, population-based, British sample with a substantial ethnic boost sample, using a face-to-face, home-based interview methodology, so standardised population data for the United Kingdom are available for reference (Robb et al; Waller et al). In addition, the CAM can be used by researchers to develop informed interven-

\section{REFERENCES}

Adlard JW, Hume MJ (2003) Cancer knowledge of the general public in the United Kingdom: survey in a primary care setting and review of the literature. Clin Oncol 15: 174-180

Bland JM, Altman DG (1997) Cronbach's alpha. BMJ 314: 572

Bowling A (2005) Mode of questionnaire administration can have serious effects on data quality. J Public Health 27: 281-291

Boyle P, Ferlay J (2005) Cancer incidence and mortality in Europe, 2004. Ann Oncol 16: $481-488$

Brunswick N, Wardle J, Jarvis MJ (2001) Public awareness of warning signs for cancer in Britain. Cancer Causes Control 12: 33- 37

Cancer Research UK (2008a) Cancer Incidence. Cancer Research UK. http:// info.cancerresearchuk.org/cancerstats/incidence/ (accessed 28 November 2008)

Cancer Research UK (2008b) Lifestyle and Cancer. Cancer Research UK. http://info.cancerresearchuk.org/cancerstats/causes/lifestyle/ (accessed 21 July 2008)

Cancer Research UK (2009) Cancer Mortality. Cancer Research UK. http://info.cancerresearchuk.org/cancerstats/mortality/timetrends/?a $=5441$ (accessed 15 January 2009)

Coleman MP, Gatta G, Verdecchia A, Esteve J, Sant M, Storm H, Allemani C, Ciccolallo L, Santaquilani M, Berrino F (2003) EUROCARE-3 summary: cancer survival in Europe at the end of the 20th century. Ann Oncol 14(Suppl 5): v128-v149

Collins D (2003) Pretesting survey instruments: an overview of cognitive methods. Qual Life Res 12: 229-238

Department of Health (2007) Cancer Reform Strategy. http://www.dh.gov.uk/ en/Publicationsandstatistics/Publications/PublicationsPolicyAndGuidance/ DH_081006 (accessed 3 December 2007)

DeVellis RF (2003) Scale Development: Theory and Applications. Sage Publications Inc.: Thousand Oaks, California

FitzGerald SC, Al Sahaf M, Furlong H, Pennycooke K, Healy C, Walsh TN (2008) Lack of awareness of oesophageal carcinoma among the public in Ireland. Ir J Med Sci 177: 151-154

Green PM, Kelly BA (2004) Colorectal cancer knowledge, perceptions, and behaviors in African Americans. Cancer Nurs 27: 206-215

Grunfeld EA, Ramirez AJ, Hunter MS, Richards MA (2002) Women's knowledge and beliefs regarding breast cancer. $\mathrm{Br} J$ Cancer 86: $1373-1378$

Kline P (2000) The Handbook of Psychological Testing. Routledge: London

Macdonald S, Macleod U, Campbell NC, Weller D, Mitchell E (2006) Systematic review of factors influencing patient and practitioner delay in diagnosis of upper gastrointestinal cancer. $\mathrm{Br} J$ Cancer 94: $1272-1280$ tions and to assess the impact of interventions designed to target gaps in public awareness of cancer either in whole populations or specific sub-groups.

\section{ACKNOWLEDGEMENTS}

The Cancer Awareness Measure was funded by Cancer Research UK and the Department of Health.

\section{Conflict of interest}

The authors declare no conflict of interest.

Marlow LAV, Waller J, Wardle J (2007) Public awareness that HPV is a risk factor for cervical cancer. Br J Cancer 97: 691-694

McCaffery K, Wardle J, Waller J (2003) Knowledge, attitudes, and behavioral intentions in relation to the early detection of colorectal cancer in the United Kingdom. Prev Med 36: 525-535

Parkin DM, Bray F, Ferlay J, Pisani P (2005) Global cancer statistics, 2002. CA Cancer J Clin 55: 74-108

Ramirez AJ, Westcombe AM, Burgess CC, Sutton S, Littlejohns P, Richards MA (1999) Factors predicting delayed presentation of symptomatic breast cancer: a systematic review. Lancet 353: 1127-1131

Redeker C, Wardle J, Wilder D, Hiom S, Miles A (2009) The launch of Cancer Research UK's 'Reduce the Risk' campaign: baseline measurements of public awareness of cancer risk factors in 2004. Eur J Cancer 45: $827-836$

Rees C, Abed R, Sheard C (2003) Development of a reliable and valid questionnaire to test the prostate cancer knowledge of men with the disease. Patient Educ Couns 51: 285-292

Richards MA, Westcombe AM, Love SB, Littlejohns P, Ramirez AJ (1999) Influence of delay on survival in patients with breast cancer: a systematic review. Lancet 353: $1119-1126$

Robb K, Stubbings S, Ramirez A, Macleod U, Austoker J, Waller J, Hiom S, Wardle J (2009) Public awareness of cancer in Britain: a populationbased survey of adults. Br J Cancer 101(Suppl 2): S18-S23

Rudberg L, Nilsson S, Wikblad K, Carlsson M (2005) Testicular cancer and testicular self-examination-knowledge and attitudes of adolescent Swedish men. Cancer Nurs 28: 256-262

Stager JL (1993) The Comprehensive Breast-Cancer Knowledge Testvalidity and reliability. J Adv Nurs 18: $1133-1140$

Streiner DL, Norman GR (1995) Health Measurement Scales: A Practical Guide to Their Development and Use. Oxford University Press: New York

Viswanath K, Breen N, Meissner H, Moser RP, Hesse B, Steele WR, Rakowski W (2006) Cancer knowledge and disparities in the information age. J Health Commun 11: 1-17

Waller J, McCaffery K, Wardle J (2004) Beliefs about the risk factors for cervical cancer in a British population sample. Prev Med 38: 745-753

Waller J, Robb K, Stubbings S, Ramirez A, Macleod U, Austoker J, Hiom S, Wardle J. Awareness of cancer symptoms and anticipated help seeking among ethnic minority groups in England. $\mathrm{Br} J$ Cancer 101(Suppl 2): S24-S30

Wardle J, Waller J, Brunswick N, Jarvis MJ (2001) Awareness of risk factors for cancer among British adults. Public Health 115: $173-174$

West R, Alkhatib MN, McNeill A, Bedi R (2006) Awareness of mouth cancer in Great Britain. Br Dent J 200: $167-169$ 